Journal of Computational and Applied Mechanics, Vol. 15, No. 2, (2020), pp. 101-114 DOI: $10.32973 /$ jcam.2020.007

\title{
DAMAGE ASSESSMENT OF THE HISTORICAL SZÉCHENYI CHAIN BRIDGE
}

\author{
LÁsZló DunAI ${ }^{a}$ AND BALÁzs Kövesdi ${ }^{a}$ \\ ${ }^{a}$ Department of Structural Engineering, Budapest University of Technology and Economics \\ H-1111 Budapest, Müegyetem rkp. 3, Hungary \\ dunai.laszlo@epito.bme.hu kovesdi.balazs@epito.bme.hu
}

[Received: June 18, 2020; Accepted: September 14, 2020]

Dedicated to Professor Barna Szabó on the occasion of his 85th birthday

\begin{abstract}
The Széchenyi Chain Bridge is a 170-year-old historical structure located in the downtown of Budapest. The superstructure of the bridge was reconstructed several times in its history and currently the renewal process of the bridge is under consideration. According to the current plans main girders, chain elements and cross-girders will remain the old structure and the deck system will be replaced by a new orthotropic steel deck. The Budapest University of Technology and Economics, Department of Structural Engineering was involved in the design process and in the assessment of the remaining elements' condition within the last 5 years. During the project authors were faced with numerous specific important and challenging structural problems, modelling specialties, advanced design methods and research interest. The main part of these unusual characteristics come from the layout of the historical structure, long time traffic and corrosion problems. One of the most important questions during the structural analysis is the condition and rotational capacity of the pins between the chain elements. The chain system is more than 100 years old and the rotational capacity of the pins is questionable due to corrosion and friction. This phenomenon significantly influences the static behaviour of the chain elements and the whole suspending system. The current paper presents the numerical and on-site experimental program on the investigation of the rotational capacity of the pins. A second important question was related to the condition of current deck system. Significant corrosion damage was observed on the steel stringers which might cause damage or local collapse of the bridge deck under public transportation loads. Advanced numerical model using probabilistic analysis (FORM) and measurement based corrosion models are applied to make a risk assessment of the deck system's capability to maintain and keep the current traffic on the bridge before the deck will be replaced. Via this bridge inspection and investigation project the authors would like to demonstrate the application of advanced numerical modelling based design techniques and the industrial application of research models for lifetime assessment and risk analysis of historical structures.
\end{abstract}

Keywords: Chain bridge, historical structure, probabilistic design, advanced numerical modeling 


\section{INTRODUCTION}

The Széchenyi Chain Bridge (Figure 1) is an almost 170-year-old historical structure of Budapest, a major attraction of the downtown over the Danube River. Although the bridge is a historical monument of Hungary and popular place for tourists, significant daily roadway traffic crosses the bridge and it is also used by the Budapest public transportation. The superstructure of the bridge was reconstructed several times in the history, but the chain elements have reached their 100-year-lifetime and the deck system is more than 70-year-old. The renewal process of the bridge is currently under organization. Fömterv Co. and MSc Ltd. made the design of the reconstruction work. The independent static check and the expert reports concerning the renewal process and damage assessment of the remaining structural elements have been completed by the Budapest University of Technology and Economics, Department of Structural Engineering in cooperation with the designers.

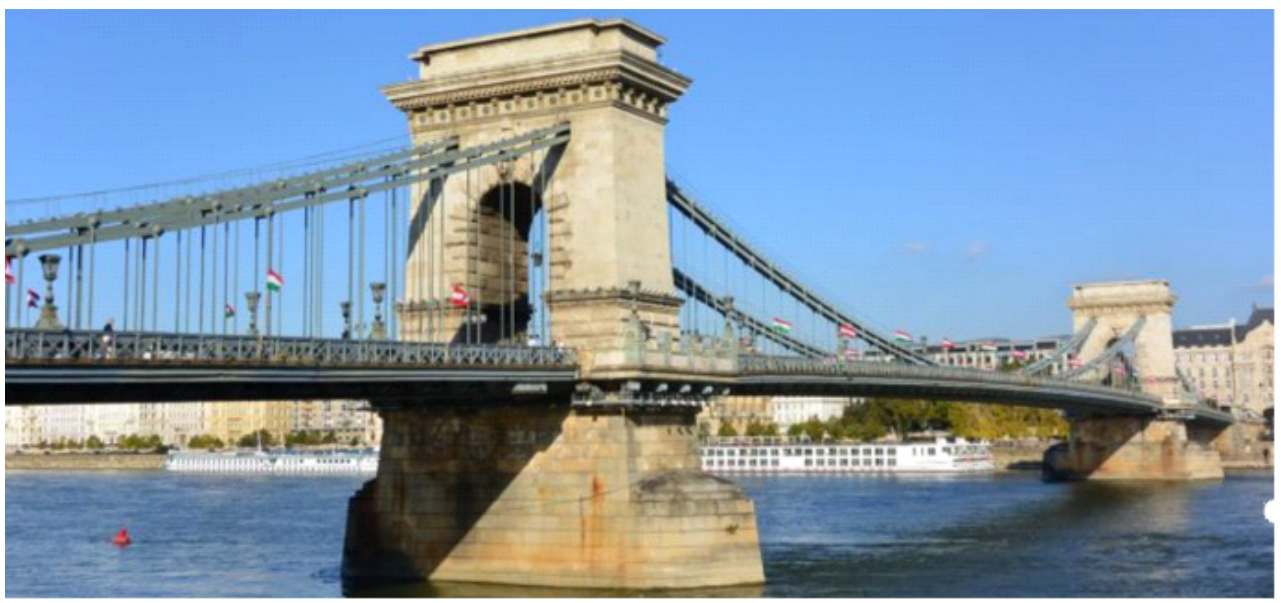

\section{Figure 1. The Széchenyi Chain Bridge 1]}

The strategy of the currently planned reconstruction is that the old bridge deck system (concrete slab and longitudinal steel stringers) will be replaced by a new orthotropic steel deck system (Figure 2). In longitudinal direction the deck system replacement will be made step-by-step, minimizing the geometry change of the suspension system during construction. The chain elements, the steel stiffening girder and the cross-girder system will remain unchanged, only the corrosion protection is planned to be renewed. Therefore, the evaluation of the structural condition of the remaining elements is an important task of the renewal process to determine their load carrying capacity and remaining lifetime.

The current paper introduces how an advanced numerical model can be used for the evaluation of the load carrying capacity of a historical structure in combination with on-site measurements and probabilistic design approach. The assessment of two structural elements are presented: (i) corroded chain elements whose pins cannot rotate due to friction and/or corrosion, (ii) old deck system with significant corrosion 


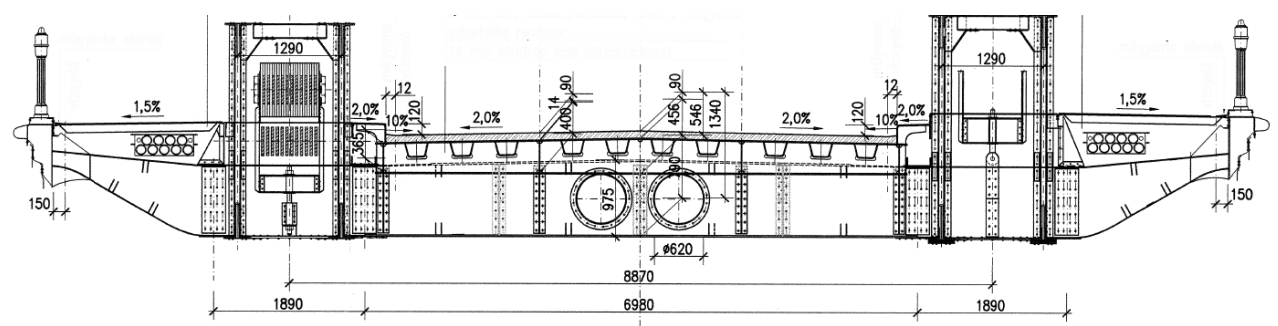

Figure 2. Planned cross-section after reconstruction 2]

damage whose risk of failure is evaluated for a short time period till reconstruction is started.

\section{History of the SzÉchenyi Chain Bridge}

The original Széchenyi Chain Bridge was erected between 1839-49 and it was considered as one of the greatest engineering works of its age (Figure 3). With a maximum middle span of $202.6 \mathrm{~m}$ this bridge was the largest chain bridge at that time; currently it is still the third one after the Herzilio Luz Bridge (339 m) in Brazil and Clifton Bridge $(214 \mathrm{~m})$ in England. The design was carried out by the English engineer William Tierney Clark while the construction was supervised by the Scottish engineer Adam Clark. The bridge was opened for traffic in 1849 and operated until 1914. Because the bridge had no stiffening girder and it had a light-weight timber deck system in this first time period, significant horizontal and vertical vibrations were observed on the bridge deck, which made the redesign of the construction necessary. The new bridge was built based on the static calculations of the Hungarian professor Antal Kherndl according to the plans of István Gállik and József Beke.

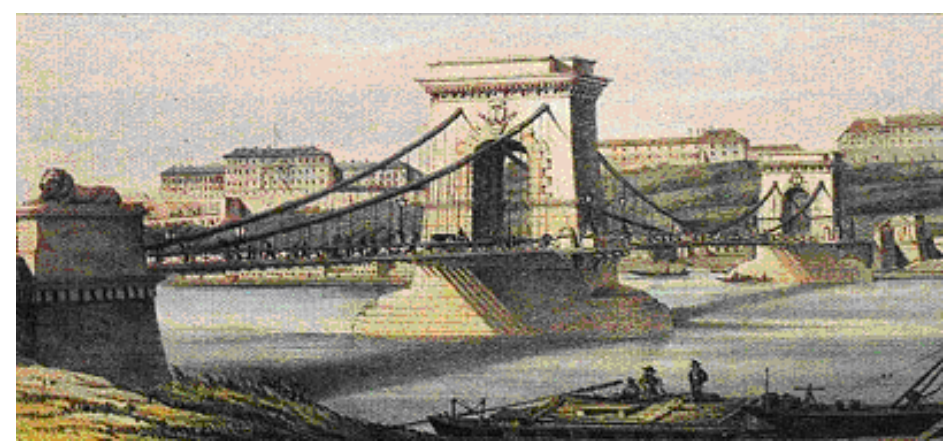

Figure 3. Planned cross-section after reconstruction [1]

The new supporting structure consisted of 25 carbon steel chain bars between each node whose length and bearing capacity was doubled compared to the previous structure (the distance between the suspension bars and the pins increased from 1.8 
$\mathrm{m}$ to $3.6 \mathrm{~m}$ ). With the new truss stiffening girder, the mass of the entire built-in ironwork grown to $5200 \mathrm{t}$ using carbon steel with tensile strength of $48-56 \mathrm{kN} / \mathrm{cm}^{2}$ (fits to the current S355 steel grade). During World War II.the bridge was demolished (in 1945) and the structure was rebuilt in its original form without any significant static changes. Two third of the chain elements were re-used, and the entire stiffening girder and deck system were replaced by new structural elements. The bridge was opened for traffic in its renewed form in 1949 1. In the meantime, no reconstruction work has been made on the system. Several investigations and measurements are made on the bridge. A loading test is performed to check the actual forces in the suspending bars; corrosion measurement were made on the chain elements in 2002; these results help the current renewal process and design.

\section{Numerical MODELING AND DESIGN ASPECTS}

The structural behavior of the bridge is studied using a numerical model developed in the general finite element program Ansys 3 . The new orthotropic deck system and the old cross-girders are modeled using higher order (8-node) thin shell elements, while the stiffening truss girder and the suspension system (hangers and chain elements) are modeled by beam elements. The general layout of the global model is shown in Figure 4 the global model consists of 193950 finite elements with a total number of 1163732 degrees of freedom. The erection phases of the bridge are simulated by birth and death process. The ultimate load calculation and risk analysis of the two analyzed structural members (chain elements and stringers of the deck system) are made using local numerical sub-models following the bridge characteristics (corrosion grade, lifetime, friction between pins and chain).

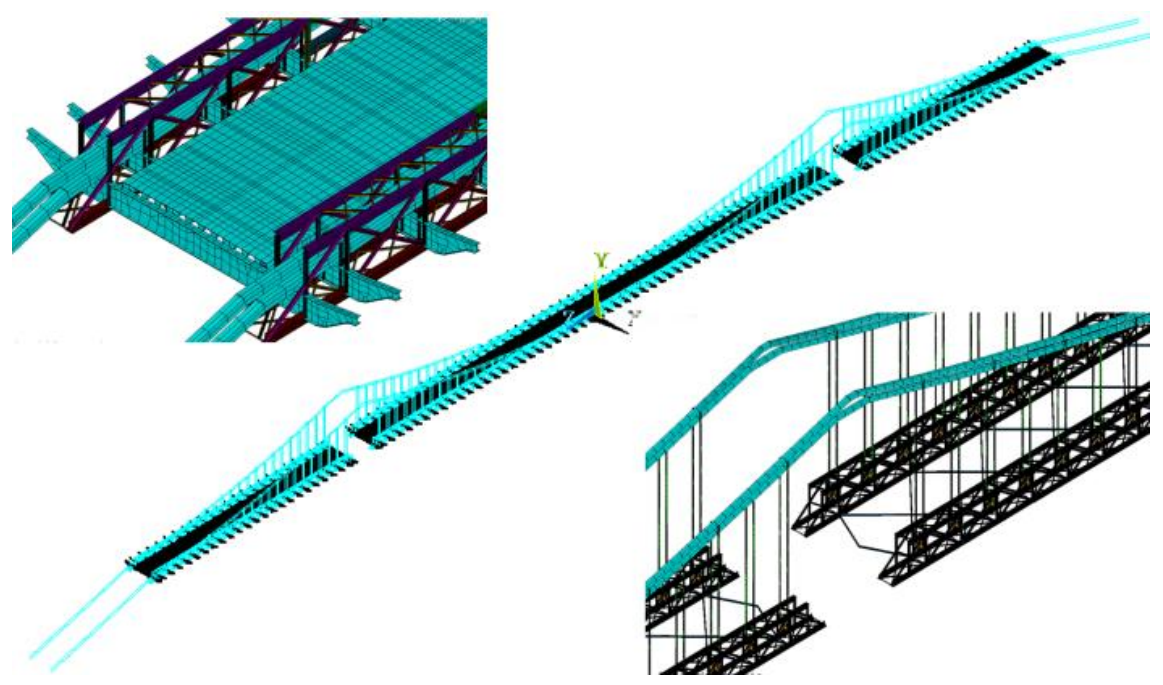

Figure 4. Global finite element model - combined shell and beam element model 
In the numerical model the following structural specialties are considered:

- original erection phases having a significant impact on the internal force distribution between the different structural members (stiffening truss girders work only for traffic loads, self-weight is carried by the chain elements alone),

- second order effects (internal force distribution between the suspension system and the deck system depends on the pretension force acting in the chains),

- rotational capacity of the pins between the chain elements (chain is subjected to dominant tension force along the entire length even if pinned joints are fixed, but significant bending moments can act at the location of the pylon and at the abutment where chain system slope significantly changes), pins can get stuck due to corrosion and/or friction resulting in bending moment in the chain elements,

- corrosion of the chains, which reduces the net cross-section of the tension system, leading to reduced tensile strength and introducing stress concentration, resulting in reduced fatigue lifetime,

- corrosion of the longitudinal steel stringers and reinforcing bars of the concrete slab, which might influence the load carrying capacity of the deck system,

- uncertainties in the corrosion grade of the bridge and changes in time increasing the risk of damage under daily traffic.

On the global numerical model geometric nonlinear analysis (GNA) is carried out in each analyzed load case combination to determine the second order internal forces and stresses. These internal forces and direct loads are applied on the local submodels where the ultimate load of the analyzed structural details are determined by geometric and material nonlinear analysis using imperfections (GMNIA) according to EN 1993-1-5 4]. The design resistance of the analyzed structural members is determined by first order reliability method (FORM) using Monte-Carlo simulation technique. This design approach can consider the uncertainties of the input data based on statistical analysis and able to perform risk assessment of the damaged structural items. Results of the FORM analysis are (i) the reliability index $(\beta)$ and (ii) reliability of the structure calculated by $P_{s}=\left(1-P_{f}\right)$, where $P_{f}$ is the risk of failure against the investigated failure mode and design lifetime. If the calculated risk of failure is larger than the prescribed value $\left(P_{0}\right)$, the structure does not fulfill the design criteria of the applied standard. The reliability index $(\beta)$ is in correlation with the risk of the failure, the relationship is given in Table 1 according to the design philosophy of Eurocode EN 1990 [5].

Table 1. Correlation between reliability index $(\beta)$ and risk of failure $\left(P_{f}\right), 5$

\begin{tabular}{|c|c|c|c|c|c|c|c|}
\hline$P_{f}$ & $10^{-1}$ & $10^{-2}$ & $10^{-3}$ & $10^{-4}$ & $10^{-5}$ & $10^{-6}$ & $10^{-7}$ \\
\hline$\beta$ & 1.28 & 2.32 & 3.09 & 3.72 & 4.27 & 4.75 & 5.20 \\
\hline
\end{tabular}

One of the most important uncertainties in case of the Széchenyi Chain Bridge is the corrosion grade. In the international literature there are numerous deterministic and stochastic corrosion models available 6 , 8 , which have been developed for 
different steel grades and environmental conditions. Authors considered corrosion using a time-dependent statistical model taken from the international literature using real measurement data as input parameters. In the current numerical model, the corrosion model developed by Paik and Kim 7 in 2012 is applied, which was originally developed for a marine environment and extended for steel bridges by Tohodi and Sharifi 6] in 2016. In this corrosion model the damage grade is considered by the Weibull-type density function given by equation (3.1):

$$
d_{c}=\frac{\alpha}{\beta} \cdot\left(\frac{Y_{e}}{\beta}\right)^{\alpha-1} \cdot \exp \left[-\left(\frac{Y_{e}}{\beta}\right)^{\alpha}\right],
$$

where: $d_{c}$ is the corrosion depth, $\alpha$ is the shape factor, $\beta$ is size factor, $Y_{e}=Y-Y_{c} ; Y$ is the age of the bridge, $Y_{c}$ is the age of the corrosion protection. Further details and the considered input parameters are given in 6 . This model can consider the change in the effectiveness of corrosion protection within the lifetime of the structure. On the other hand, it can also consider how the likelihood of the corrosion depth changes over time depending on the corrosion grade. In the applied numerical model of the chain elements, on-site measurement data from 2002 are implemented as initial input data of the corrosion model. Corroded surface is fitted on a large number of corrosion measurement data which is implemented in a solid finite element model.

\section{ON-SITE MEASUREMENTS ON THE CHAIN ELEMENTS}

To check the rotational capacity of the pins an on-site loading test is executed on the bridge. The aim of the test was to determine the change in the normal force and bending moment within the chain elements. From the measured bending moment, conclusion could be made on the rotation ability of the pins (thus rotation reduces or totally eliminates bending moment). Results of the numerical model show the typical moment diagram of the suspension system (Figure 5b) if all pins become stuck (fixed connections are assumed in the numerical model). Results prove a significant bending moment can develop only within the chain elements at the two sides of the pylons and at the abutments. Therefore, these are the places where stress changes were measured during the loading test using strain gauges. All the other joints behave quasipinned, even if they are modeled by fixed joints. The bridge was loaded by 12 trucks

(a)

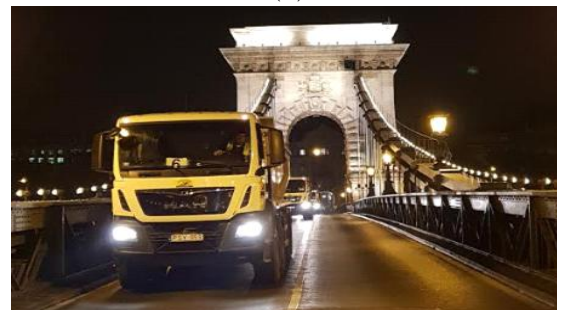

(b)

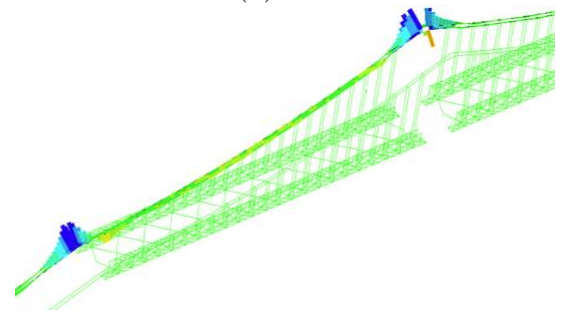

Figure 5. a) On-site loading test and b) calculated bending moment diagram with fixed pins 
(Figure 5a) with an average weight of $200 \mathrm{kN}$, placed in 13 different loading arrangements simulating partial and total loading situations. The following measurements are executed within the loading test program:

- deflection measurements to check the global behavior of the system,

- strain measurements at 8 chain elements to determine the normal stress changes (normal force and bending moments separately),

- influence line measurements on the chain to check the global structural behavior due to moving loads,

- eigenfrequency measurements.

Deformation measurement results show the maximum measured deflection was slightly smaller than the numerically calculated maximum displacement, which predicted certain sticking effect and confirmed that the chain system has larger stiffness than predicted by the numerical model. Strain gauge measurements are also evaluated. Normal force and bending moment changes are determined in each investigated chain element, which are also compared to the numerical results. Results proved that from the 8 analyzed pins only one pin could rotate under the applied load. All other pins got stuck and could not rotate under the applied test load. One example for the measured normal stresses is presented in Figure6. The diagram shows the strain measurement results while 3 trucks are moving on the bridge and take their planned position. Strain gauges H3/1 - H3/6 are placed on the outermost fiber of the first chain element next to the abutment and others are located on the second one, serving as reference measurements (dominant tension force was expected on the second chain elements). Results give evidence on the developed bending moment resulting from the stuck pins. Numbering of the strain gauges followed the same strategy at each measuring location. Strain gauges around the abutment are signed by H4 abutments are investigated during the on-site measurements marked by H1 - H4 and 10 strain gauges are placed on the chain elements at each measuring location, resulting in the code of the strain gauges (e.g. H3/1, etc.).

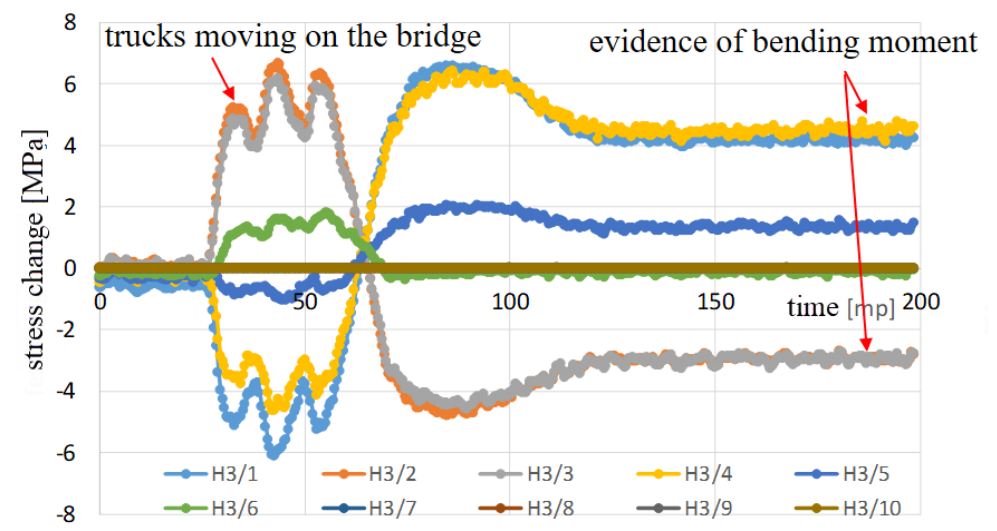

Figure 6 . Stress changes in one chain element due to loading by 3 trucks 
Strain measurement results show normal force level difference between the two sides of the pylon. This can only happen if roller supports cannot move on the top of the pylons, showing significant friction or sticking effect. This fact can also be seen on the measured influence lines presented in Figure 7 .

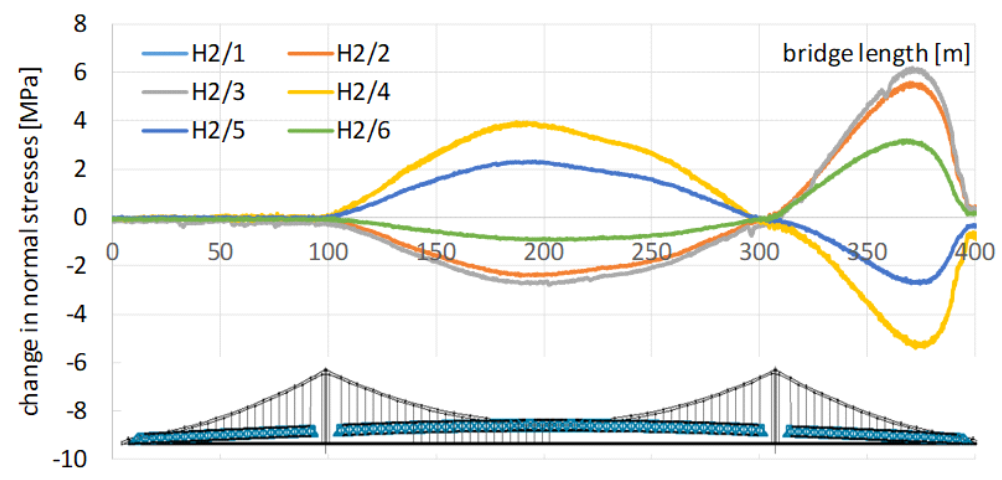

Figure 7. Influence line of one chain element

Measurement shows there are no measured strains for the left side span of the bridge, which can only happen if significant horizontal force is carried by the roller supports. On-site measurement results gave essential information to the designers and confirmed chain elements should be checked for bending and normal force interaction $(\mathrm{N}+\mathrm{M}$ interaction).

\section{Resistance CAlCUlation of CORRoded AND STUCKed CHAin ElEMENTS}

It is well known that stuck pins change the structural behavior of the chain elements, which could lead to damage if they are not designed or statically checked. One of the most serious chain bridge failures occurred in the USA in 1967 and resulted in the death of 46 people 9 . The Silver Bridge collapsed due to a single chain element failure initiated from a fatigue crack, resulting in the total collapse of the chain system. The reason for the failure was the sticking of the pins due to corrosion. Therefore, it is a crucial point to check the resistance and risk of failure of the chain for combined
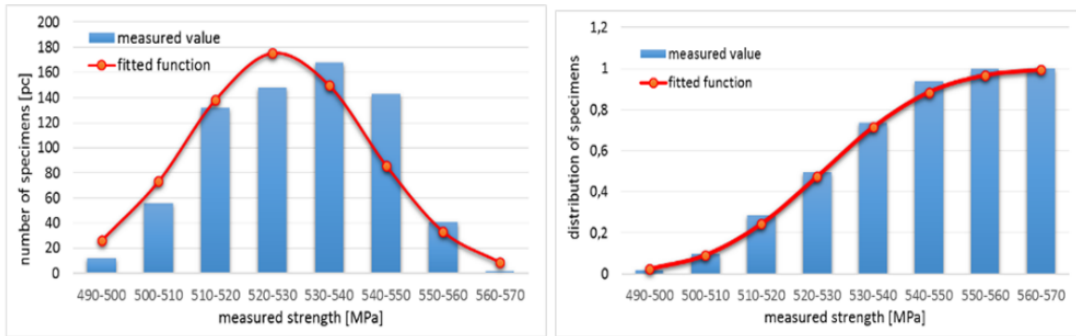

Figure 8. Material properties of the chain elements based on coupon tests 
normal force and bending moment ( $\mathrm{N}+\mathrm{M}$ interaction) considering corrosion and stuck pins. The corrosion grade, old material properties and other design parameters have large scatter, which can only be considered in probability based design approaches. The main part $(76 \%)$ of the chain elements was manufactured in 1915 [1] with the characteristic of the contemporary steel manufacturing techniques. Results of 702 coupon tests taken in 1912 were found by the authors in the literature. So, the mean and characteristic values of the steel material could be determined by statistical evaluation and probabilistic curve fitting, as shown in Figure 8.

Advanced solid element based numerical model is developed for the analysis of the chain elements. Contact elements are applied between the connected surfaces considering friction and sticking effect. The developed numerical models have the following capabilities:

- elasto-plastic material behaviour using damage criteria to model tensile fracture of the material,

- friction and sticking between the pin and chain elements, - considering the measured corrosion grade based on the measured surface properties and its probability on the surface of the chain elements,

- ultimate load is determined using geometrical and material nonlinear analysis using imperfections (GMNI analysis),

- coupling GMNI analysis (numerical simulations) with the probabilistic design approach.
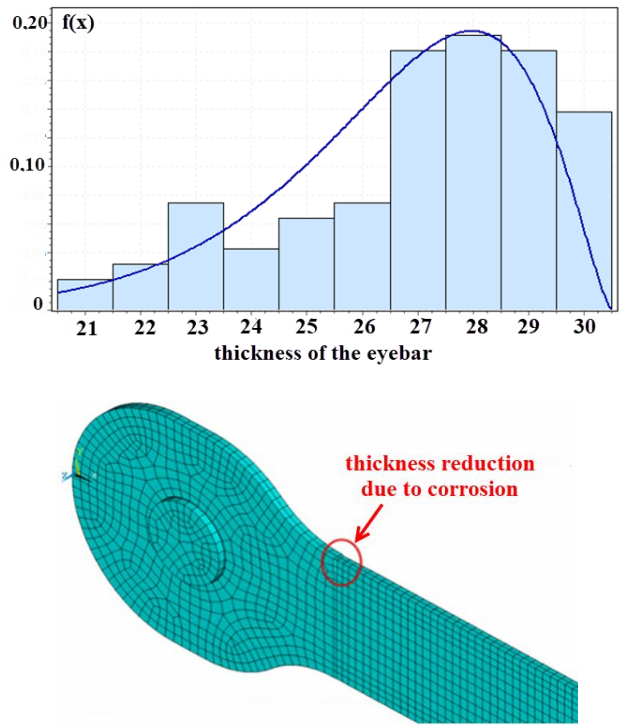

Figure 9. Model of the corroded surface and its probabilistic distribution

Considering corrosion of the chain elements, measured mean surface is implemented into the numerical model and distribution function is determined and graded by the 
Kolmogorov-Szmirnov test. Beta distribution function was found to be accurate in most cases to model the corrosion uncertainties, therefore this probabilistic function was implemented in the numerical model. The mean corrosion surface and the applied beta distribution function are presented in Figure 9 .

Probabilistic analysis is carried out on the numerical model using the Monte-Carlo simulation technique, generating pseudorandom values for the defined variable parameters using Latin hypercube sample selection. In each single case the ultimate resistance is determined using GMNI analysis by evaluation of the obtained loaddisplacement curve. During probabilistic analysis the following variables are considered:

- depth of the chain elements (using $\mathrm{CoV}=0.005$ ),

- thickness of the chain elements (using $\mathrm{CoV}=0.05$ ),

- yield strength of the steel (using $\mathrm{CoV}=0.03$ - based on measurements),

- corrosion grade (using Beta distribution function - based on measurements).

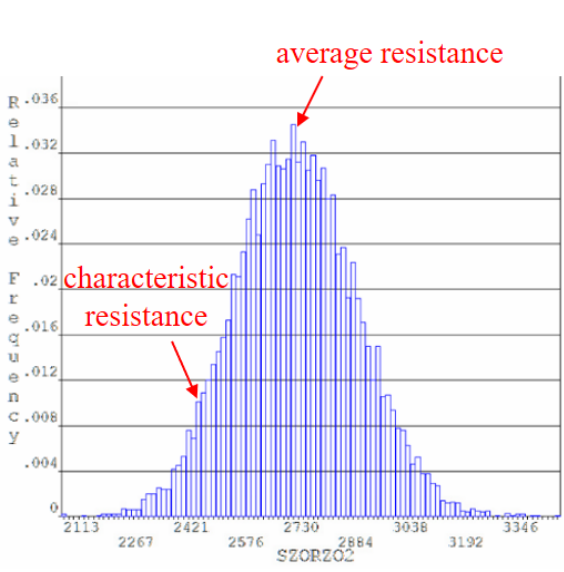

a) distribution function of the characteristic resistances

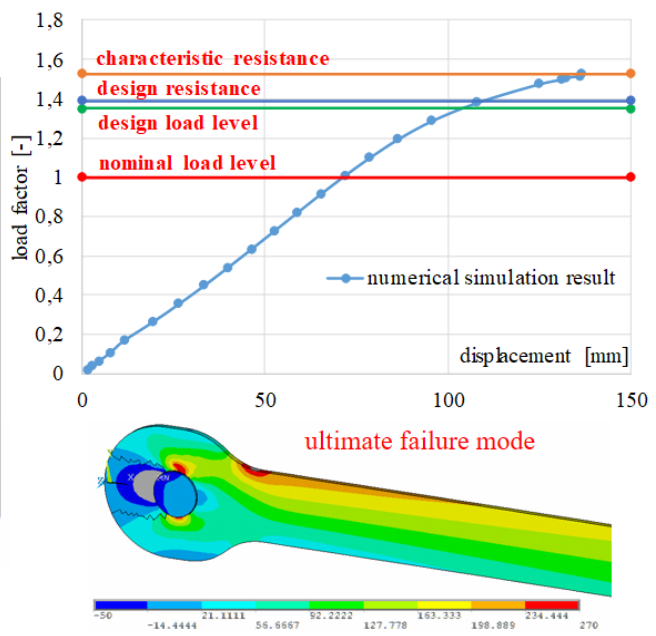

b) typical load-displacement curve and obtained failure mode

Figure 10. Results of the combined probabilistic design method with the GMNI analyses

In the frame of the probabilistic analysis a total of 20000 numerical analyses (using the surface fitting method) are executed within the Monte-Carlo simulation at a confidence level of $95 \%$. One example for the numerical GMNI analysis result is presented in Figure 10, showing a load-displacement curve around the average resistance level from all the simulation results. In each calculation, the characteristic resistances are determined referring to different input values. Based on the obtained results the average, the characteristic and design values of the resistance are determined by statistical evaluation, as shown in Figure 10. Results of the probabilistic design showed that the average value of the resistance is $158 \%$ of the actual internal force. The $5 \%$ lower quantile value is equal to $148 \%$ representing the characteristic value. The $0.1 \%$ 
quantile value is equal by $138 \%$ representing the design resistance level. This value is larger than the design value of the acting loads (135\% of the nominal load level). So the corroded chain element satisfies the design criteria for $\mathrm{N}+\mathrm{M}$ interaction with a maximum utilization ratio of $98 \%$.

\section{RisK ASSESSMENT OF THE DECK SYSTEM}

Another structural component where corrosion grade can lead to damage of the structure is the bridge deck system. The aim of the investigation was to determine the risk of failure of the deck considering on-site measurement data, real loading situation with public transportation using a probabilistic design approach. Locations and the extent of corrosion were taken into consideration in the numerical model based on onsite measurements carried out in 2019. Two photographs of the corroded longitudinal stringers are presented in Figure 11 showing the worst case locations.
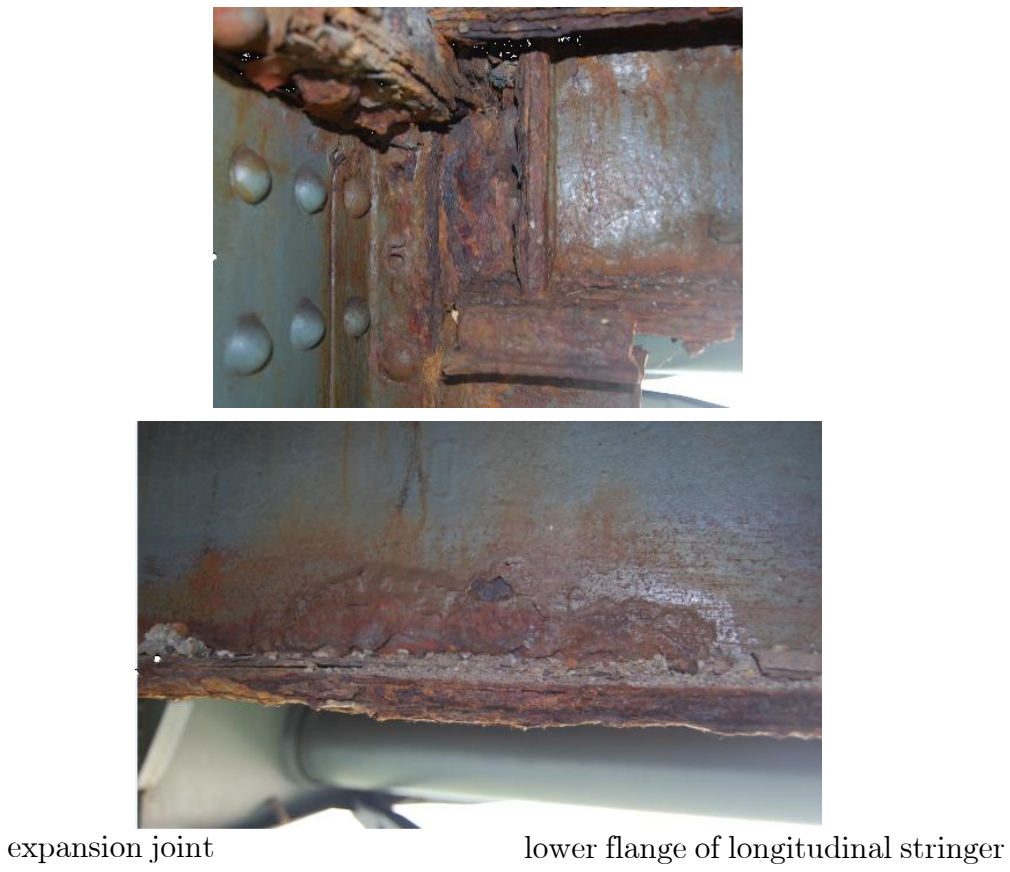

Figure 11. Corroded structural details of the deck system

Based on the on-site corrosion measurements, the following average corrosion damage grades (or corrosion waste, i.e., reduction of thickness) are taken into account in the numerical model:

- upper and lower flanges of the outer longitudinal stringer: $50 \%$,

- web of the outer longitudinal stringer: 30\%,

- web, upper and lower flanges of the inner longitudinal stringer: 10\%,

- upper and lower flanges of the outer longitudinal stringer near to the expansion joint: $50 \%$, 
- web of the outer longitudinal stringer near to the expansion joint: $80 \%$,

- reinforcing bars at the bottom of the slab: $30 \%$.

The given values are considered in the initial configuration for deterministic analysis, while in the stochastic analysis these are considered as mean values of the corresponding probability density function. Two standard cross-sections are analysed: i) longitudinal stringers near to the expansion joint and ii) internal longitudinal stringers in general location. Isometric and cross-sectional views of the sub-model are shown in Figure 12 .

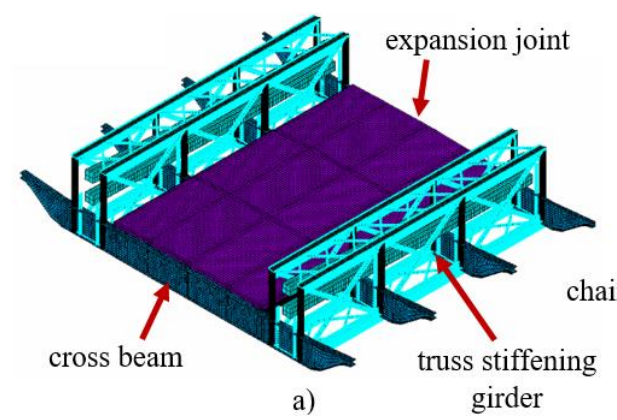

a)

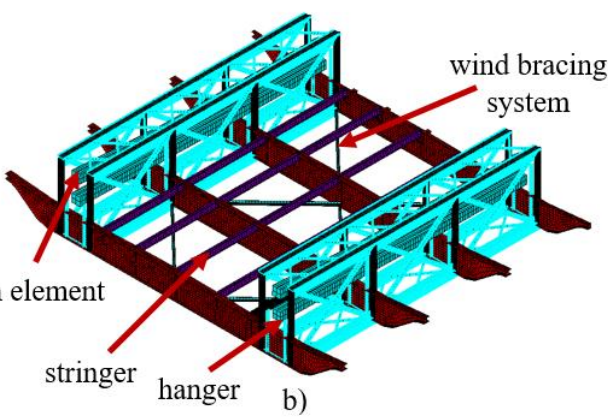

c)

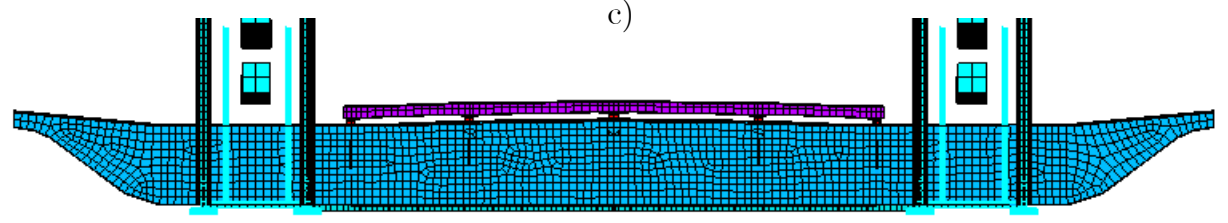

Figure 12. Isometric view of the model a) with and b) without reinforced concrete slab, c) cross-sectional view

Our check of the reinforced concrete slab in ultimate limit state is partially based on analytical calculations as height of the compression zone is pre-calculated in the analyzed cases, assuming that tensile strength of the concrete can be ignored. Thus, finite elements in the tensile zones having concrete material models are inactivated. An automatic algorithm is developed to determine the extension of cracking in all load cases and the numerical model is rebuilt considering crack locations and relevant material properties. On-site measurements show the largest damage risk is at the vicinity of expansion joints, where corrosion grade of the web reaches $80 \%$, traffic load results in maximum shear force and dynamic effect is also at its maximum due to the expansion joint. At this location the failure mode obtained by the numerical calculations is shear buckling of the web, as shown in Figure 13 . The numerical simulation based resistance is interpreted and calculated according to EN 1993-1-5 [4] recommendations. 


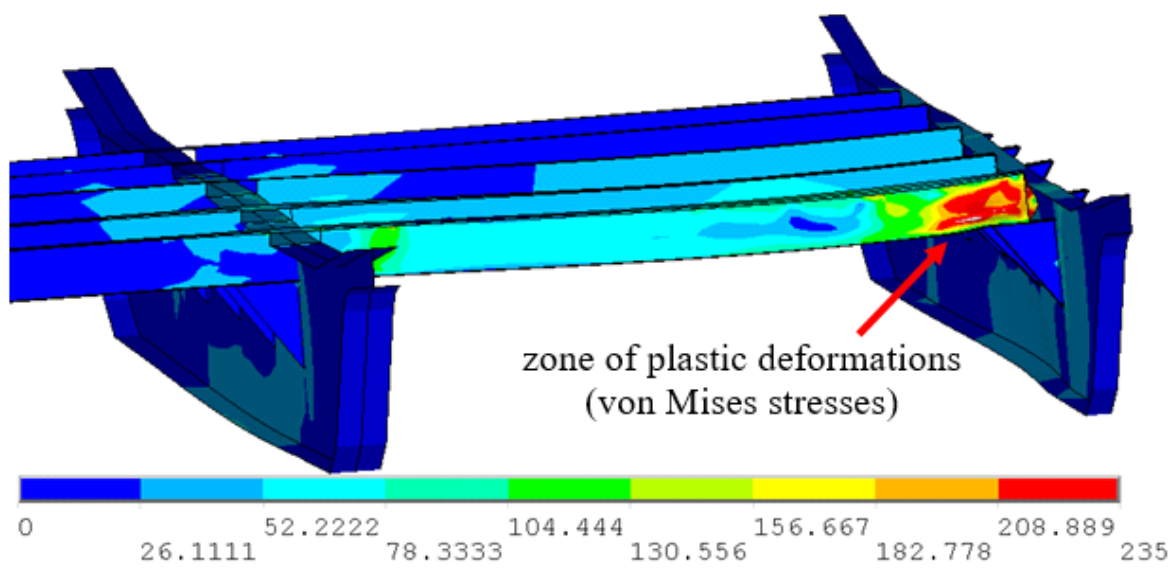

Figure 13. Failure mechanism and von Mises stresses $[\mathrm{MPa}]$

Based on the deterministic calculation the characteristic value of the load factor is equal to $\alpha=1.05$ (considering design load case combination). Deterministic calculations proved that the vicinity of the expansion joint has a high utilization ratio, therefore risk of failure is also determined. Stochastic analysis is carried out focusing on the worst case loading situation and corresponding failure mode (shear buckling of stringer web). The density function of the calculated ultimate load factors based on Monte-Carlo simulation is shown in Figure 14. The load factors are determined by GMNI analysis, which is combined with the probability approach.

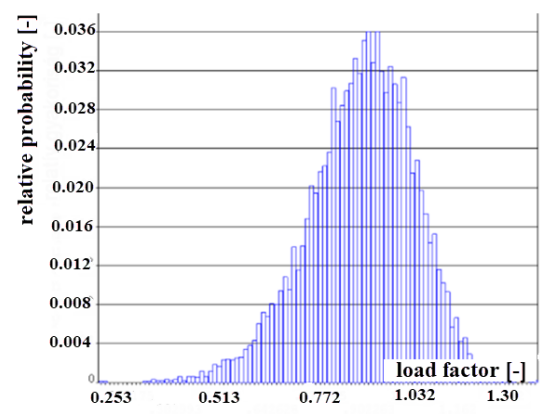

Figure 14. Density function of load factors based on Monte Carlo simulation

A relatively large coefficient of variation is obtained, which is a result of the corrosion model, with its high level of uncertainty associated with corrosion damage depth. The mean value of calculated ultimate load factors, denoting the failure of the structure, is 1.40 , while the standard deviation is 0.206 (maximum axle load of buses in service on the bridge is $125 \mathrm{kN}$ and considered dynamic amplification factor on the deck system is 1.40). From the statistical evaluation the calculated reliability index $(\beta)$ is equal to 2.43 , which corresponds to the failure probability of $0.007448(1 / 134)$. 


\section{Summary}

The present paper has the aim to demonstrate the application of advanced numerical modelling techniques and probabilistic design approaches in the civil engineering praxis. The Széchenyi Chain Bridge is one of the most important monuments and national symbols of Hungary, and its renewal process is currently under organization. The executed numerical calculations could help designers and decision makers in the evaluation of the actual condition, remaining lifetime, risk of damage of the corroded chain elements and deck system. In the applied numerical calculations a probabilistic design approach is combined with geometrical and material nonlinear analysis using imperfections. In the deterministic and stochastic analysis the results of the on-site measurements are considered regarding the corrosion grade, rotational capacity of the pins and material properties of the chain elements.

Acknowledgement. The authors would like to express special thanks to the Fömterv Zrt. design office for providing information related to the historical bridge, and for their cooperation concerning both the expert reports and the evaluation of the on-site measurements.

\section{REFERENCES}

1. S. Domanovszky. Száz éve, 1915. november 27-én helyezték forgalomba az átépített Lánchidat [The rebuilt Chane Bridge was put in circulation one hundred years ago on November 27, 1915]. TEXT Nyomdaipari Kft., 2015.

2. 10-I-002-01. Static calculation of the superstructure of the Széchenyi chain bridge. MSc Kft., Főmterv - MSc - Céh Konzorcium, tsz: 8300, 23.08.2016. Shop drawings.

3. ANSYS $^{\otimes}$ v15.0, Canonsburg, Pennsylvania, USA.

4. EN 1993-1-5. Eurocode 3: Design of steel structures - Part 1.5: Plated structural elements, 2006.

5. EN 1990. Eurocode - Bases of structural design, 2002.

6. S. Tohodi and Y. Sharifi. "Load-carrying capacity of locally corroded steel plate girder ends using artificial neural network." Thin-Walled Structures, 100, (2016), pp. 48-61. DOI: $10.1016 / \mathrm{j}$.tws.2015.12.007.

7. J. K. Paik and D. K. Kim. "Advanced method for the development of an empirical model to predict time-dependent corrosion wastage." Corrosion Science, $\mathbf{6 3}$, (2012), pp. 51-58. DOI: 10.1016/j.corsci.2012.05.015.

8. S. Wang Y.and $\mathrm{Xu}, \mathrm{H}$. Wang, and $\mathrm{A}$. Li. "Predicting the residual strength and deformability of corroded steel plate based on the corrosion morphology." Construction and Building Materials, 152, (2017), p. 777.

9. B. Äkesson. Understanding Bridge Collapses. Taylor \& Francis Group, 2008, pp. 139-148. 